\title{
Basic studies on life circumstances and stress in persons with congenital physical disabilities using always wheelchairs
}

\author{
Yoshimasa Matsuura $^{1^{*}}$, Shinichi Demura ${ }^{2}$, Yoshiharu Tanaka $^{3}$, Hiroki Sugiura ${ }^{4}$ \\ ${ }^{1}$ Research Organization for University-Community Collaboration, Osaka Prefecture University, Osaka, Japan; \\ *Corresponding Author: matsuura@las.osakafu-u.ac.jp \\ ${ }^{2}$ Graduate School of Natural Science \& Technology, Kanazawa University, Kanazawa, Japan \\ ${ }^{3}$ Faculty of Liberal Arts and Sciences, Osaka Prefecture University, Osaka, Japan \\ ${ }^{4}$ Graduate School of Natural Science \& Technology, Kanazawa University, Kanazawa, Japan
}

Received 19 September 2012; revised 25 October 2012; accepted 1 November 2012

\section{ABSTRACT}

Many studies about the health problems of persons with physical disabilities have been performed, however few studies have focused on the life circumstances of persons with physical disabilities. This study aimed to clarify the relationship between stress and the life circumstances of persons with congenital physical disabilities who must use wheelchairs. The participants were $\mathbf{7 0}$ individuals who used the services of care workers employed by welfare service business offices. Participants used wheel-chairs. In addition, those participants who used a standard manual wheelchair were not able to operate it alone. Participants were required to answer a two-part questionnaire with questions about factors related to basic lifestyle and stress, and about life factors related to the stress of individuals with physical disabilities. No signifycant relationship between lifestyle and stress was found in either males or females. Most persons with congenital physical disabilities using wheelchairs had some kind of stress in daily life. In particular, significantly more level of stress was found in females $(90 \%)$ than that in males (65\%). Levels of stress according to life factor differed between males and females. The most dramatic gender difference was that the level of stress caused by the mental or mind factor in females was significantly higher than that in males $(p<0.05)$. Most persons who must use wheelchairs have stress resulting from daily life, and in particular, females experience more mental stress than males.

Keywords: Life Habit; Persons with Physical
Disabilities; Stress

\section{INTRODUCTION}

Recently, because of advances in social, cultural, and environmental support, living in the general community has become easier for persons with physical disabilities. However, their tasks of daily life, mainly preparing meals, laundry, and housekeeping, are supported by home helpers or care workers.

In addition, because individuals with physical disabilities often need assistance when leaving their homes, they always receive some limitations regarding movements or norms from the helpers. Furthermore, although four barriers (physical, institutional, cultural and informational, and psychological barriers) surrounding persons with physical disabilities are gradually improving, these barriers still limit their everyday life to some extent.

In particular, transportation support (Guide Help Service) for their social participation is limited by the financial situation and social welfare policy of each community. This situation surely increases the individuals' mental stress, limits their social participation, and therefore, negatively affects their health conditions.

Many studies about the health problems of persons with physical disabilities, specifically, the relationship between disability and stress, have been performed [1-19]. Sunghee et al. [20] investigated daily stress in 70 elders with arthritis and clarified that the elders' stress was significantly related to social support and greatly influenced by the support of care workers.

Deborah et al. [21] studied the relationship between disability and stress using the Stanford Health Assessment Questionnaire (HAQ) for 42 women with systemic lupus erythematosus (SLE). They reported that stress in their daily lives was actually caused by negative life events rather than disease-related factors, and therefore, 
the stress management of daily life was essential.

Nakayama et al. [22] analyzed the results of stress factors on persons with physical disabilities, coupled with the results of stress reduction effects on persons who adopted swimming for exercise. They reported that general stress factors were significantly greater in persons with physical disabilities $(\mathrm{p}<0.05)$ than in those with generally good health, and persons with physical disabilities had high rates of inappropriate coping methods such as overeating and overdrinking.

In addition, they divided persons with physical disabilities into exercise/sports and non-exercise/sports groups, and then, compared the degree of stress, stress factors, and stress coping methods. The results showed lower degrees of stress, fewer stress factors, and higher rates of adequate stress coping methods (e.g., music appreciation, creative work) in the exercise/sports group. Therefore, they concluded that exercise/sports would be an effective method for reducing stress in persons with physical disabilities.

As stated above, significant studies on stress in persons with acquired diseases and on the stress-relieving method by the intervention of exercise have been performed. However, few studies have focused on the relationship between the life circumstances and stress of persons with severe physical disabilities who must use wheelchairs.

This study aims to clarify the relationship between stress and lifestyle or life factors in persons with congenital physical disabilities who must always use wheelchairs.

\section{METHODS}

\subsection{Participants}

The participants in this study were 70 persons with congenital physical disabilities (40 males and 30 females), using services of care workers employed by welfare service business offices. For mobility, the participants always used a power-assisted wheelchair or a standard manual wheelchair. In addition, the participants who used a standard manual wheelchair were not able to operate it alone.

We obtained informed consent from the participants and care workers after explaining to them the purpose and content of the experiment in detail. A questionnaire was used to gather data; the time frame was from September to November, 2010. The care workers of the welfare service establishments distributed the questionnaire, and they also returned them in a closed and confidential condition.

Those participants who were physically able to write filled out the questionnaire themselves. If the participant was physically unable to fill out the questionnaire, a family member or the care worker acted as amanuensis.
The questionnaire consisted of two parts, questions on basic lifestyle and life factors related to stress, discussed in the following two sections.

\subsection{Questionnaire on Basic Lifestyle}

For the questions about basic lifestyle, following seven factors were selected: 1) Wake-up time, 2) Bedtime, 3) Sleeping period, 4) Breakfast intake, 5) Snack situation, 6) Evacuation situation, and 7) Living conditions. Respondents provided the average for these activities during one week.

The responses on each lifestyle factor were divided into two groups to examine the relationship with stress, as follows:

The mean wake-up time was 7:40 $\pm 1 \mathrm{~h} 16 \mathrm{~min}$, and therefore, the participants were divided into two groups at the borderline of 8:00 a.m. The mean bedtime was 23:07 $\pm 1 \mathrm{~h} 24 \mathrm{~min}$, and therefore, the participants were divided into two groups at the borderline of 23:00 p.m. In short, participants who wake up before 8:00 a.m. are "early-to-rise"; and participants who go to bed before 23:00 are "early-to-bed."

The mean sleeping period was $8 \mathrm{~h} 32 \mathrm{~min} \pm 1 \mathrm{~h} 32$ $\mathrm{min}$, and therefore, the participants were divided into two groups at the borderline of $8 \mathrm{~h}$. In short, participants who slept over $8 \mathrm{~h}$ were judged to be "long-sleep" persons.

The sleeping period was divided at $8 \mathrm{~h}$ because the mean was $8 \mathrm{~h} 32 \mathrm{~min}$, which is very close to one-third of a day $(8 \mathrm{~h})$ and is a general sleeping period for adults. The other four factors in this study (breakfast intake, snack situation, evacuation situation, and living conditions) were reported as four possible categories. For breakfast intake, the participants were divided into two groups according to the frequency of response: 1) Always eat breakfast group, and 2) A group consisting of the sum of participants who almost always eat breakfast, sometimes eat breakfast, and never eat breakfast.

For the factor of snack situation, the respondents were divided into two groups, i.e., participants that answered 1) Snack every day or snack sometimes, and 2) Snack very little or no snack at all. For the factor of evacuation situation, the respondents were divided into two groups, i.e., participants that answered 1) Every day or almost every day, and 2) Once every two or three days, or irregularly. For living conditions, respondents were again divided into two groups according to frequency of response, i.e., participants that answered 1) Living alone and 2) Living with parents or living with family and parents or living with family other than parents.

\subsection{Questionnaire on Life Factors Related to Stress in Persons with Physical Disabilities}

Even elderly persons without physical disabilities 
experience stress induced by various aspects of living (e.g., sleeping, preparing meals, bathing, housekeeping, relations with family).

Referring to previous studies [23-26], including the questionnaire of Michele et al. [27] which focused on wheelchair users, ten life factors were chosen for this study: 1) Disability, 2) Body, 3) Mind, 4) Family relationships, 5) Sleep, 6) Meals, 7) Bathing, 8) Relationship with care worker, 9) Housekeeping, 10) Going out.

Responses were given in four categories of stress level frequency: 1) Most of the time, 2) Sometimes, 3) Seldom, and 4) Not at all. According to the frequency of response, the subjects were divided into a stress group and non-stress group. The stress group felt significantly stressed or sometimes stressed (categories 1 and 2). The non-stress group felt little or no stress (categories 3 and 4).

Data on stress for these life factors were analyzed from the following five viewpoints:

1) Does stress differ according to type of disability, age, or gender?

2) Does stress relate to life habit?

3) Does stress relate to the life factors considered to be the cause of stress?

4) Which life factor is most strongly related to stress?

5) Is there a gender difference in stress related to the life factors?

In addition, physical disabilities were divided into a "cerebral paralysis" group and an "other physical disorders" group. The latter group was composed of persons with disorders such as muscular dystrophy, rheumatism, soma dysfunction, trunk functional disorder, functional disorder of upper limbs, functional disorder of lower limbs. To examine the stress according to age, the participants were classified into the following five groups: 1) Over 60 years, 2) From 50 to 60 years, 3) From 40 to 50 years, 4) From 30 to 40 years, and 5) Under 30 years.

\subsection{Statistical Analysis}

The difference of mean values between the stress group and non-stress group was examined by t-test. The difference and independence among category frequencies were examined by chi square test. The level of significance was set at 0.05 . It was adjusted with $\alpha^{\prime}=0.05 / \mathrm{n}$ (n: number of the comparison) by Bonferroni's method.

\section{RESULTS}

Table 1 shows the age distribution of persons with physical disabilities. The greatest number (21) of participants by age category were in their 50 s for both males (13) and females (8). Mean ages were 43.2 years for males and 47.6 years for females.

Table 2 shows the number, percentage, and test results of stress frequency according to physical disability, age, and gender. Differences between the group with cerebral

Table 1. Age distribution of persons with physical disabilities.

\begin{tabular}{cccccccc}
\hline & $20 \mathrm{~s}$ & $30 \mathrm{~s}$ & $40 \mathrm{~s}$ & $50 \mathrm{~s}$ & $60 \mathrm{~s}$ & $70 \mathrm{~s}$ & total \\
\hline Total & 10 & 16 & 16 & 21 & 3 & 4 & 70 \\
Male & 7 & 8 & 11 & 13 & 0 & 1 & 40 \\
Female & 3 & 8 & 5 & 8 & 3 & 3 & 30 \\
\hline
\end{tabular}

Table 2. Differences between groups for the presence of stress in daily life.

\begin{tabular}{|c|c|c|c|c|c|}
\hline & \multirow{2}{*}{ kinds } & \multicolumn{2}{|c|}{ Do you feel some stress in daily life? } & \multicolumn{2}{|r|}{$\chi_{0}^{2}$ value } \\
\hline & & Considerably or highly & Slightly or not at all & Total & $\chi_{0}^{2}$ \\
\hline \multirow{3}{*}{ Disabilities } & Other physical disabilities & $23(67.6 \%)$ & $11(32.4 \%)$ & 34 & \multirow{3}{*}{2.34} \\
\hline & & & & & \\
\hline & Cerebral paralysis & $30(83.3 \%)$ & $6(16.7 \%)$ & 36 & \\
\hline \multirow{5}{*}{ Generation } & $60 \leq \mathrm{n}$ & $6(85.7 \%)$ & $1(14.3 \%)$ & 7 & \multirow{5}{*}{1.997} \\
\hline & $50 \leq \mathrm{n}<60$ & $16(76.2 \%)$ & $5(23.8 \%)$ & 21 & \\
\hline & $40 \leq \mathrm{n}<50$ & $12(75.0 \%)$ & $4(25.0 \%)$ & 16 & \\
\hline & $30 \leq \mathrm{n}<40$ & $13(81.3 \%)$ & $3(18.8 \%)$ & 16 & \\
\hline & $\mathrm{n}<30$ & $6(60.0 \%)$ & $4(40.0 \%)$ & 10 & \\
\hline \multirow{3}{*}{ Gender } & Male & $26(65.0 \%)$ & $14(35.0 \%)$ & 40 & \multirow{3}{*}{$5.827^{*}$} \\
\hline & & & & & \\
\hline & Female & $27(90.0 \%)$ & $3(10.0 \%)$ & 30 & \\
\hline
\end{tabular}


paralysis and the group with other physical disabilities (see the Methods section, above) were insignificant. In addition, differences among age groups were found to be insignificant. However, a significant difference was found in the stress levels between males $(65 \%)$ and females $(90 \%)$, females obviously reporting much higher levels of stress.

Because a significant gender difference was found, further analysis was performed according to gender (Tables 3 and 4).
Tables 3 and $\mathbf{4}$ show the relationship between life habits and stress according to gender. No significant relationships were found in either males or females.

Figure 1 shows a bar graph ordering the life factors of stress based on the frequency of response of the participants. For all participants, the highest level of stress was caused by body $(35.7 \%)$, followed by that caused by mind $(30.0 \%)$, disability $(27.1 \%)$, relationship with care worker $(25.7 \%)$, family relationships $(21.0 \%)$, and sleep (15.7\%).

Table 3. Relationships between life habits and stress in males.

\begin{tabular}{|c|c|c|c|c|}
\hline \multirow{2}{*}{ Stress } & \multicolumn{3}{|c|}{ Wake-up time } & \multirow{2}{*}{$\frac{\chi_{0}^{2} \text { value }}{\chi_{0}^{2}}$} \\
\hline & Before 8:00 am & After 8:00 am & Total & \\
\hline Present & $14(53.8 \%)$ & $12(46.2 \%)$ & 26 & \multirow{2}{*}{0.010} \\
\hline \multirow[t]{3}{*}{ Absent } & $7(50.0 \%)$ & $7(50.0 \%)$ & 14 & \\
\hline & \multicolumn{3}{|c|}{ Bed-time } & $\chi_{0}^{2}$ value \\
\hline & Before 23:00 pm & After 23:00 pm & Total & $\chi_{0}^{2}$ \\
\hline Present & $8(30.8 \%)$ & $18(69.2 \%)$ & 26 & \multirow{2}{*}{1.653} \\
\hline \multirow[t]{3}{*}{ Absent } & $8(57.1 \%)$ & $6(42.9 \%)$ & 14 & \\
\hline & \multicolumn{3}{|c|}{ Sleeping period } & $\chi_{0}^{2}$ value \\
\hline & Under eight hours & Over eight hours & Total & $\chi_{0}^{2}$ \\
\hline Present & $13(50.0 \%)$ & $13(50.0 \%)$ & 26 & \multirow{2}{*}{0.284} \\
\hline \multirow[t]{3}{*}{ Absent } & $5(35.7 \%)$ & $9(64.3 \%)$ & 14 & \\
\hline & \multicolumn{2}{|c|}{ Do you usually eat breakfast? } & & $\chi_{0}^{2}$ value \\
\hline & Everyday & Sometimes or not eat at all & Total & $\chi_{0}^{2}$ \\
\hline Present & $19(73.1 \%)$ & $7(26.9 \%)$ & 26 & \multirow{2}{*}{0.047} \\
\hline \multirow[t]{3}{*}{ Absent } & $9(64.3 \%)$ & $5(35.7 \%)$ & 14 & \\
\hline & \multicolumn{2}{|c|}{ How about your evacuation situation? } & & $\chi_{0}^{2}$ value \\
\hline & Sometime or everyday & Irregular or once per two or three days & Total & $\chi_{0}^{2}$ \\
\hline Present & $19(73.1 \%)$ & $7(26.9 \%)$ & 26 & \multirow{2}{*}{2.374} \\
\hline \multirow[t]{3}{*}{ Absent } & $6(42.9 \%)$ & $8(57.1 \%)$ & 14 & \\
\hline & \multicolumn{2}{|c|}{ Do you have snack between meals? } & & $\chi_{0}^{2}$ value \\
\hline & Sometime or everyday & A little or not at all & Total & $\chi_{0}^{2}$ \\
\hline Present & $5(19.2 \%)$ & $21(80.8 \%)$ & 26 & \multirow{2}{*}{0.002} \\
\hline \multirow[t]{3}{*}{ Absent } & $2(14.3 \%)$ & $12(85.7 \%)$ & 14 & \\
\hline & & ife or live with parents? & & $\chi_{0}^{2}$ value \\
\hline & Single life & Live with parents & Total & $\chi_{0}^{2}$ \\
\hline Present & $8(30.8 \%)$ & $18(69.2 \%)$ & 26 & \multirow{2}{*}{0.586} \\
\hline Absent & $2(14.3 \%)$ & $12(85.7 \%)$ & 14 & \\
\hline
\end{tabular}


Table 4. Relationships between life habits and stress in females.

\begin{tabular}{|c|c|c|c|c|}
\hline \multirow{2}{*}{ Stress } & \multicolumn{3}{|c|}{ Wake-up time } & \multirow{2}{*}{$\frac{\chi_{0}^{2} \text { value }}{\chi_{0}^{2}}$} \\
\hline & Before 8:00 am & After 8:00 am & Total & \\
\hline Present & $19(70.4 \%)$ & $8(29.6 \%)$ & 27 & \multirow{2}{*}{3.126} \\
\hline \multirow[t]{3}{*}{ Absent } & $0(0.0 \%)$ & $3(100 \%)$ & 3 & \\
\hline & \multicolumn{3}{|c|}{ Bed-time } & $\chi_{0}^{2}$ value \\
\hline & Before 23:00 pm & After 23:00 pm & Total & $\chi_{0}^{2}$ \\
\hline Present & $10(37.0 \%)$ & $17(63.0 \%)$ & 27 & \multirow{2}{*}{0.139} \\
\hline \multirow[t]{3}{*}{ Absent } & $2(66.7 \%)$ & $1(33.3 \%)$ & 3 & \\
\hline & \multicolumn{3}{|c|}{ Sleeping period } & $\chi_{0}^{2}$ value \\
\hline & Under eight hours & Over eight hours & Total & $\chi_{0}^{2}$ \\
\hline Present & $15(55.6 \%)$ & $12(44.4 \%)$ & 27 & \multirow{2}{*}{0.015} \\
\hline \multirow[t]{3}{*}{ Absent } & $1(33.3 \%)$ & $2(66.7 \%)$ & 3 & \\
\hline & \multicolumn{2}{|c|}{ Do you usually eat breakfast? } & & $\chi_{0}^{2}$ value \\
\hline & Everyday & Sometimes or not eat at all & Total & $\chi_{0}^{2}$ \\
\hline Present & $14(51.9 \%)$ & $13(48.1 \%)$ & 27 & \multirow{2}{*}{0.015} \\
\hline \multirow[t]{3}{*}{ Absent } & $2(66.7 \%)$ & $1(33.3 \%)$ & 3 & \\
\hline & \multicolumn{2}{|c|}{ How about your evacuation situation? } & & $\chi_{0}^{2}$ value \\
\hline & Sometime or everyday & Irregular or once per two or three days & Total & $\chi_{0}^{2}$ \\
\hline Present & $21(77.8 \%)$ & $6(22.2 \%)$ & 27 & \multirow{2}{*}{0.928} \\
\hline \multirow[t]{3}{*}{ Absent } & $1(33.3 \%)$ & $2(66.7 \%)$ & 3 & \\
\hline & \multicolumn{2}{|c|}{ Do you have snack between meals? } & & $\chi_{0}^{2}$ value \\
\hline & Sometime or everyday & A little or not at all & Total & $\chi_{0}^{2}$ \\
\hline Present & $4(14.8 \%)$ & $23(85.2 \%)$ & 27 & \multirow{2}{*}{0.032} \\
\hline \multirow[t]{3}{*}{ Absent } & $0(0.0 \%)$ & $3(100 \%)$ & 3 & \\
\hline & \multicolumn{2}{|c|}{ Single life or live with parents? } & & $\chi_{0}^{2}$ value \\
\hline & Single life & Live with parents & Total & $\chi_{0}^{2}$ \\
\hline Present & $9(33.3 \%)$ & $18(66.7 \%)$ & 27 & \multirow{2}{*}{0.282} \\
\hline Absent & $0(0.0 \%)$ & $3(100 \%)$ & 3 & \\
\hline
\end{tabular}

Similarly, in males, stress caused by body $(30 \%)$ was the highest level of stress, followed by that by disability (27.5\%), family relationships $(20.0 \%)$, relationship with care worker $(17.5 \%)$, sleep $(15.0 \%)$. In males, mind $(12.5 \%)$ showed the lowest level causing stress. However, in females, mind $(53.3 \%)$ showed the highest level causing stress, followed by body (43.3\%), relationship with care worker $(36.7 \%)$, disability $(26.7 \%)$, family relationships $(23.3 \%)$, and sleep (16.7\%). In short, life factors for stress showed differing tendencies between males and females.

Table 5 shows the test results of gender differences for each life factor causing stress. Only the factors of mind, preparing meals, and housekeeping showed significant differences $(p<0.05)$. In addition, higher levels of stress caused by all factors were reported in females than those of males.

\section{DISCUSSION}

Many persons with physical disabilities live without using a wheelchair. In addition, among persons with physical disabilities who do use wheelchairs, many have acquired physical disabilities and can handle wheelchairs by themselves. 


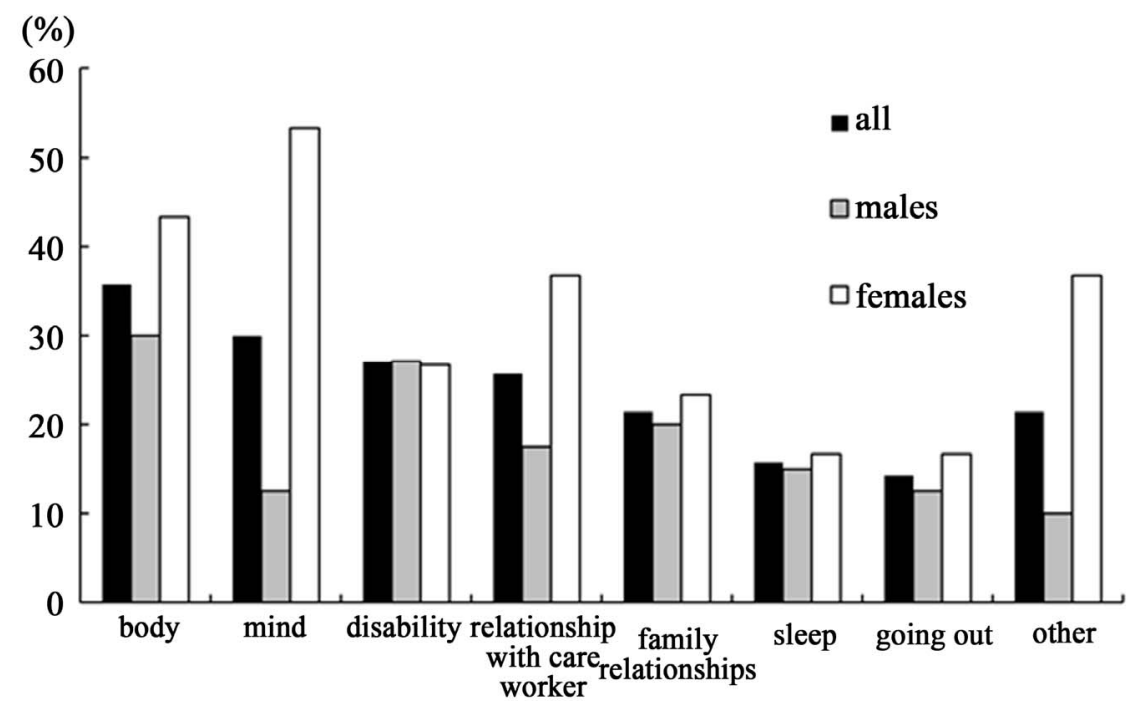

Figure 1. Levels of stress caused by life factors.

Table 5. Gender differences of life factors causing stress.

\begin{tabular}{|c|c|c|c|c|c|}
\hline & \multirow{2}{*}{ Gender } & \multicolumn{2}{|c|}{ Is the factor cause stress on you? } & \multicolumn{2}{|r|}{$\chi_{0}^{2}$ value } \\
\hline & & Yes & No & Total & $\chi_{0}^{2}$ \\
\hline \multirow[b]{2}{*}{ Disability } & Male & $11(27.5 \%)$ & $29(72.5 \%)$ & 40 & \multirow{2}{*}{0.006} \\
\hline & Female & $8(26.7 \%)$ & $22(73.3 \%)$ & 30 & \\
\hline \multirow{2}{*}{ Body } & Male & $12(30.0 \%)$ & $28(70.0 \%)$ & 40 & \multirow{2}{*}{1.327} \\
\hline & Female & $13(43.3 \%)$ & $17(56.7 \%)$ & 30 & \\
\hline \multirow{2}{*}{ Mind } & Male & $5(12.5 \%)$ & $35(87.5 \%)$ & 40 & \multirow{2}{*}{$13.611^{* * *}$} \\
\hline & Female & $16(53.3 \%)$ & $14(46.7 \%)$ & 30 & \\
\hline \multirow{2}{*}{ Family relationships } & Male & $8(20.0 \%)$ & $32(80.0 \%)$ & 40 & \multirow{2}{*}{0.113} \\
\hline & Female & $7(23.3 \%)$ & $23(76.7 \%)$ & 30 & \\
\hline \multirow{2}{*}{ Sleep } & Male & $6(15.0 \%)$ & $34(85.0 \%)$ & 40 & \multirow{2}{*}{0.036} \\
\hline & Female & $5(16.7 \%)$ & $25(83.3 \%)$ & 30 & \\
\hline \multirow{2}{*}{ Meal } & Male & $0(0.0 \%)$ & $40(100 \%)$ & 40 & \multirow{2}{*}{$5.657^{*}$} \\
\hline & Female & $4(13.3 \%)$ & $26(86.7 \%)$ & 30 & \\
\hline \multirow{2}{*}{ Bathing } & Male & $1(2.5 \%)$ & $39(97.5 \%)$ & 40 & \multirow{2}{*}{0.726} \\
\hline & Female & $2(6.7 \%)$ & $28(93.3 \%)$ & 30 & \\
\hline \multirow{2}{*}{ Relationship with care worker } & Male & $7(17.5 \%)$ & $33(82.5 \%)$ & 40 & \multirow{2}{*}{3.297} \\
\hline & Female & $11(36.7 \%)$ & $19(63.3 \%)$ & 30 & \\
\hline \multirow{2}{*}{ House } & Male & $0(0.0 \%)$ & $40(100 \%)$ & 40 & \multirow{2}{*}{$4.179^{*}$} \\
\hline & Female & $3(10.0 \%)$ & $27(90.0 \%)$ & 30 & \\
\hline \multirow{2}{*}{ Going out } & Male & $5(12.5 \%)$ & $35(87.5 \%)$ & 40 & \multirow{2}{*}{0.243} \\
\hline & Female & $5(16.7 \%)$ & $25(83.3 \%)$ & 30 & \\
\hline \multirow{2}{*}{ Others } & Male & $3(7.5 \%)$ & $37(92.5 \%)$ & 40 & \multirow{2}{*}{0.018} \\
\hline & Female & $2(6.7 \%)$ & $28(93.3 \%)$ & 30 & \\
\hline
\end{tabular}


Michele et al. [27]. examined disability-related stress for persons with acquired physical disabilities who always use wheelchairs. However, few stress studies have focused only on persons with extremely serious congenital physical disabilities who must use wheelchairs. For the latter, the wheelchair plays a role as a part of the body because of greater limitations in daily life. Therefore, these individuals are thought to have greater stress than those with a disability who do not need a wheelchair.

At first, this study aimed to examine differences by types of disability, generation, and gender in stress and stress resulting from life factors in persons with congenital physical disabilities who must use wheelchairs for mobility.

The results clarified that many of these individuals experience some kind of stress in daily life. However, differences between the cerebral paralysis group (83\%) and the other physical disability group (about 68\%) were insignificant. From these percentages, we can infer that many persons with congenital physical disabilities who need a wheelchair experience stress, regardless of the type of disability.

The percentages of participants who feel stress in each age group were as follows: the category under 30 years had the least $(60 \%)$, and that over 60 years had the most $(85.7 \%)$. Each of the other categories (30 - 40 years, 40 50 years, and 50 - 60 years) reported $75 \%$ - 86\% stress. Because insignificant differences were found among age groups, persons with congenital physical disabilities are inferred to have great stress regardless of age.

A significant difference was found between males and females; the rate of females' stress $(90 \%)$ was higher than that of males' (65\%). Michele et al. [27] aimed to develop a disability-related stress scale of wheelchair users, surveying 71 males and 48 females with acquired physical disabilities. However, they did not examine gender differences.

On the other hand, significant relationships between any life habit and stress were not found in either males or females. In other words, differences in life factors may not be the direct cause of stress in persons with physical disabilities regardless of gender. The fact that care workers perform appropriate tasks in everyday life, according to the individual's demand, may be one reason for these results.

Among life factors, the highest factor for stress in males was body $(30.0 \%)$, but that in females was mind $(53.3 \%)$. Other high levels of stress as a result of life factors revealed differing tendencies between males and females (see the Results section, above).

Stress levels caused by the body factor were high (first highest in males, second highest in females). This result, of course, is attributable to the study being limited to persons with congenital physical disabilities.

As background to the above result, anxiety about the lack of human communication and female-specific psycho-physiology are considered to be important factors. In particular, 70\% (19 among 27) of the female participants had cerebral paralysis; possibly these participants could not communicate well with other people, including the care worker, because of their language disorder and athetosis (involuntary movement).

In females, the third highest stress factor was relationship with care worker $(36.7 \%)$, even higher than body factor $(30.0 \%)$, which was the highest in males. Therefore, females in particular may feel high stress toward care workers. This finding calls for further examination of such stress. On the other hand, care workers' stress should also be examined in relation to this factor.

In gender differences of stress levels according to life factor, females showed significantly higher stress rates in the three factors: mind, preparing meals, and housekeeping than that in males. Therefore, we may infer that females, even among persons with congenital physical disabilities, feel more stress about the state of the household than males.

In general, females have been said to have higher rates of depression than males because of the instability of physiological hormone secretions [28-30], social problems arising from perceived gender differences, and/or stress from life events. According to statistics by epidemiological investigations, the lifetime prevalence of depression in females is about two times that in males [31].

In addition, females seem to have a higher probability for the prevalence of psychiatric disorders as well as depression than males [32]. Hence, high mental stress in females is considered to depend on female-specific psycho-physiology, regardless of the presence or absence of disabilities. Therefore, we may infer that the results in this study reflected gender difference of the mental stress factor.

In general, the ratio between males and females of anorexia nervosa and bulimia nervosa causing stress is said to be one to ten [33]. As background, this ratio seems to relate to females' greater sensitivity to physical style, proportion, and increases or decreases in weight.

In conclusion, many persons with congenital physical disabilities depending on wheelchairs feel some kind of stress in daily life, irrespective of age and type of disability. In addition, more females (90\%) suffer stress than males $(65 \%)$. The relationship between stress and life habit was not found. The order of higher life factors causing stress is different between males and females, and females have the highest stress caused by the mental factor, and the percentage of stress caused by this factor in females is higher than that in males. 


\section{ACKNOWLEDGEMENTS}

This study's protocol was ethically approved by Department of Education, Kanazawa University.

We are grateful to the persons with physical disabilities co-operated with this study. This study was mostly supported by the funds of Japan Society for the Promotion of Science Grant-in Aid for Science Research base study (C) for from 2009 to 2011, the furtherance of problem number 21500656 .

\section{REFERENCES}

[1] Barlow, J.H., Powell, L.A., Gilchrist, M. and Fotiadou, M. (2008) The effectiveness of the training and support program for parents of children with disabilities: A randomized controlled trial. Journal Psychosomatic Research, 64, 55-62. doi:10.1016/j.jpsychores.2007.06.006

[2] Draper, P. and Brocklehurst, H. (2007) The impact of stroke on the well-being of the patient's spouse: An exploratory study. Journal of Clinical Nursing, 16, 264-271. doi:10.1111/j.1365-2702.2006.01575.x

[3] Dudley, S.K. and Carr, J.M. (2004) Vigilance: The experience of parents staying at the bedside of hospitalized children. Journal of Pediatric Nursing, 19, 267-275. doi:10.1016/j.pedn.2004.05.008

[4] Hong, S.W. (2009) Factors influencing health-related quality of life in Korean medicaid beneficiaries. Journal of Korean Academy of Nursing, 39, 480-489. doi:10.4040/jkan.2009.39.4.480

[5] Hung, J.W., Wu, Y.H., Chiang, Y.C., Wu, W.C. and Yeh, C.H. (2010) Mental health of parents having children with physical disabilities. Chang Gung Medical Journal, 33, 82-91.

[6] Huntington. A. and Gilmour, J.A. (2005) A life shaped by pain: Women and endometriosis. Journal of Clinical Nursing, 14, 1124-1132. doi:10.1111/j.1365-2702.2005.01231.x

[7] Isaksson, A.K. and Ahlstrom, G. (2006) From symptom to diagnosis: Illness experiences of multiple sclerosis patients. Journal of Neuroscience Nursing, 38, 229-237. doi:10.1097/01376517-200608000-00005

[8] Kalpakjian, C.Z., Toussaint, L.L., Quint, E.H. and Reame, N.K. (2005) Use of a standardized menopause symptom rating scale in a sample of women with physical disabilities. Menopause, 12, 78-87. doi:10.1097/00042192-200512010-00014

[9] Misajon, R., Pallant, J.F., Manderson, L. and Chirawatkul, S. (2008) Measuring the impact of health problems among adults with limited mobility in Thailand: further validation of the perceived impact of problem profile. Health and Quality of Life Outcomes, 21, 6. doi:10.1186/1477-7525-6-6

[10] Misajon, R., Manderson, L., Pallant, J.F., Omar, Z., Bennett, E. and Rahim, R.B. (2006) Impact, distress and HRQoL among Malaysian men and women with a mobility impairment. Health and Quality of Life Outcomes, 12 , 95. doi:10.1186/1477-7525-4-95

[11] Rintala, D.H., Loubser, P.G., Castro, J., Hart, K.A. and
Fuhrer, M.J. (1998) Chronic pain in a community-based sample of men with spinal cord injury: Prevalence, severity, and relationship with impairment, disability, handicap, and subjective well-being. Archives of Physical Medicine and Rehabilitation, 79, 604-614. doi:10.1016/S0003-9993(98)90032-6

[12] Saub, R., Locker, D., Allison, P. and Disman, M. (2007) Cross-cultural adaptation of the oral helth impact profile (OHIP) for the Malaysian adult population. Community Dental Health, 24, 166-175.

[13] Sterling, M. and Chadwick, B.J. (2010) Psychologic processes in dairy life with chronic whiplash: Relations of posttraumatic stress symptoms and fear-of-pain to hourly pain and uptime. Clinical Journal of Pain, 26, 573-582. doi:10.1097/AJP.0b013e3181e5c25e

[14] Sullivan, M., Ormel, J., Kempen, G.I. and Tymstra, T. (1998) Beliefs concerning death, dying, and hastening death among older, functionally impaired Dutch adults: A one-year longitudinal study. Journal of the American Geriatrics Society, 46, 1251-1257.

[15] Taanila, A., Kokkonen, J. and Jarvelin, M.R. (1996) The long-term effects of children's early-onset disability on marital relationships. Developmental Medicine \& Child Neurology, 38, 567-577. doi:10.1111/j.1469-8749.1996.tb12121.x

[16] Tate, D., Forchheimer, M., Maynard, F. and Dijkers, M. (1994) Predicting depression and psychological distress in persons with spinal cord injury based on indicators of handicap. American Journal of Physical Medicine \& Rehabilitation, 73, 175-183. doi:10.1097/00002060-199406000-00006

[17] Wood, K.D. and Johnston, M.V. (2000) Measuring the capacity of families to provide unpaid support for a disabled family member: Using BIGSTEPS to identify primary and secondary dimensions. Journal Outcome Measures, 4, 453-460.

[18] Warmuz, A., Szeliga, D., Krzemień, G., Stemplewska, B. and Witanowska, J. (2004) Rehabilitation of patients after lower limb amputation as a basic element of adaptation to normal life. Wiad Lek, 57, 331-334.

[19] Yantzi, N., Rosenberg, M.W., Burke, S.O. and Harrison, M.B. (2001) The impacts of distance to hospital on families with a child with a chronic condition. Social Science \& Medicine, 52, 1777-1791. doi:10.1016/S0277-9536(00)00297-5

[20] Sunghee, H.T., Hong, S.H. and Kennedy, R. (2007) Daily stress in elders with arthritis. Nursing \& Health Sciences, 9, 29-33. doi:10.1111/j.1442-2018.2007.00301.x

[21] Deborah, D.C., Dokkin, P.L., Pinard, L., Fortin, P.R., Danoff, D.S., Esdaile, J.M. and Clarke, A.E. (1999) The role of stress in Functional disability among women with systemic lupus erythematosus; a prospective study. $A r$ thritis Care and Research, 12, 112-119. doi:10.1002/1529-0131(199904)12:2<112::AID-ART6 $>3$ $.0 . \mathrm{CO} ; 2-2$

[22] Nakayama, M., Kimura, Y., Kurihara, A., Tanaka, S. and Kakiyama, Y. (2007) An inspection on the stress factor analysis toward the physically handicapped persons, and on the stress reduction effect at the adopted swimming 
exercise of them. Journal Faculty Education Saga University, 11, 307-315.

[23] Sato, S., Demura, S., Minami, M. and Kasuga, K. (2002) Longitudinal assessment of ADL ability of partially dependent elderly people: examining the utility of the index and characteristics of longitudinal change in ADL ability. Journal of Physiological Anthropology and Applied Human Science, 21, 179-187. doi:10.2114/ipa.21.179

[24] Sato, S., Demura, S., Kobayashi, H. and Nagasawa, Y. (2002) The relationship and its change with aging between ADL and daily life satisfaction characteristics in independent Japanese elderly living at home. Journal of Physiological Anthropology and Applied Human Science, 21, 195-204. doi:10.2114/jpa.21.195

[25] Demura, S., Sato, S., Yokoya, T. and Sato, T. (2010) Examination of useful items for the assessment of fall risk in the community-dwelling elderly Japanese population. Environmental Health and Preventive Medicine, 15, 169179. doi:10.1007/s12199-009-0124-7

[26] Demura, S., Sato, S., Yamaji, S., Kasuga, K. and Nagasawa, Y. (2011) Examination of validity of fall risk assessment items for screening high fall risk elderly among the healthy community-dwelling Japanese population. Archives of Gerontology and Geriatrics, 53, 41-45. doi:10.1016/j.archger.2010.10.010

[27] Michele, F. and Connor, J.P. (2007) The measurement of disability-related stress in wheelchair users. Archives of
Physical Medicine and Rehabilitation, 88, 1260-1267. doi:10.1016/j.apmr.2007.06.763

[28] Fairburn, C.G. and Harrison, P.J. (2003) Eating disorders. Lancet, 361, 407-416. doi:10.1016/S0140-6736(03)12378-1

[29] Steinhausen, H.C. (2002) The outcome of anorexia nervosa in the 20th century. American Journal of Psychiatry, 159, 1284-1293. doi:10.1176/appi.ajp.159.8.1284

[30] Willer, M.G., Thuras, P. and Crow, S.J. (2005) Implications of the changing use of hospitalization to treat anorexia nervosa. American Journal of Psychiatry, 162, 2374-2376. doi:10.1176/appi.ajp.162.12.2374

[31] Sartorius, N. (1992) The ICD-10 classification of mental and behavioural disorders. Clinical Descriptions and Diagnostic Guidelines. World Health Organization, Geneva, 8-21.

[32] Silverman, J.A. (1977) Anorexia nervosa: Historical perspective on treatment. In Garner D.M. and Garfinkel P.E., Ed., Handbook of Treatment for Eating Disorders, Guilford Press, New York, 3-10.

[33] Bulik, C.M., Laura, M.T., Tammy, L., Pisetsky, E.M., Lichtenstein, P. and Pedersen, N.L. (2010) Understanding the relation between anorexia nervosa and bulimia nervosa in a Swedish national twin sample. Biological Psychiatry, 67, 71-77. doi:10.1016/j.biopsych.2009.08.010 